it is possible that deprivation may contribute to under-reporting of exacerbations with less chance of treating these events. ${ }^{13}$ Meanwhile, it is important to advise patients - especially those with a history of frequent exacerbations - to take advantage of home insulation grants and to wear warm clothes when going outside the home, as this should reduce winter hospital admissions for COPD exacerbations.

Conflicts of interest The authors declare that they have no conflicts of interest in relation to this article

Commissioned article; not externally peer-reviewed; accepted 10th August 2013; online 19th August 2013

(C) 2013 Primary Care Respiratory Society UK. All rights reserved

http://dx.doi.org/10.4104/pcrj.2013.00078

Prim Care Respir J 2013; 22(3): 264-265

\section{References}

1. Wedzicha JA, Brill SE, James P Allinson JP, Donaldson GC. Mechanisms and impact of the frequent exacerbator phenotype in chronic obstructive pulmonary disease BMC Medicine 2013;11:181. http://dx.doi.org/10.1186/1741-7015-11-181

2. McAllister DA, Morling JR, Fischbacher CM, MacNee W, Wild SH. Socioeconomic deprivation increases the effect of winter on admissions to hospital with COPD: retrospective analysis of 10 years of national hospitalisation data. Prim Care Respir J 2013;22(3):296-9. http://dx.doi.org/10.4104/pcrj.2013.00066

3. Shah S, Peacock J. Deprivation and excess winter mortality. Journal of epidemiology and community health 1999;53(8):499-502.

http://dx.doi.org/10.1136/jech.53.8.499

4. Lawlor DA, Maxwell R, Wheeler BW. Rurality, deprivation, and excess winter mortality: an ecological study. J Epidemiol Community Health 2002;56(5):373-4. http://dx.doi.org/10.1136/jech.56.5.373

5. Lawlor DA, Harvey D, Dews HG. Investigation of the association between excess winter mortality and socio-economic deprivation. J Public Health Med 2000;22(2):176-81. http://dx.doi.org/10.1093/pubmed/22.2.176

6. Aylin P, Morris S, Wakefield J, Grossinho A, Jarup L, Elliott P. Temperature, housing, deprivation and their relationship to excess winter mortality in Great Britain, 19861996. Int J Epidemio/ 2001;30(5):1100-08. http://dx.doi.org/10.1093/ije/30.5.1100

7. Donaldson GC, Keatinge WR. Cold related mortality in England and Wales; influence of social class in working and retired age groups. Epidemiol. Community Health 2003;57(10):790-91. http://dx.doi.org/10.1136/jech.57.10.790

8. Liddell C, Morris, C. Fuel Povertiy and human health: A review of recent evidence. Energy Policy 2010;38:2987-97. http://dx.doi.org/10.1016/j.enpol.2010.01.037

9. Keatinge WR, Donaldson GC. Changes in mortalities and hospital admissions associated with holidays and respiratory illness: implications for medical services. J Eval Clin Pract 2005;11(3):275-81.

http://dx.doi.org/10.1111/j.1365-2753.2005.00533.x

10. Donaldson GC, Keatinge WR. Early increases in ischaemic heart disease mortality dissociated from and later changes associated with respiratory mortality after cold weather in south east England. J Epidemiol Community Health 1997;51(6):643-8. http://dx.doi.org/10.1136/jech.51.6.643

11. Keatinge WR. Seasonal mortality among elderly people with unrestricted home heating. BMJ (Clin Res Ed) 1986;293(6549):732-3.

12. Keatinge $W$, Donaldson G. Winter deaths: warm housing is not enough. BMJ 2001;323(7305):166-7. http://dx.doi.org/10.1136/bmj.323.7305.166/a

13. Seemungal TAR, Donaldson GC, Paul EA, Bestall JC, Jeffries DJ, Wedzicha JA. Effect of exacerbation on quality of life in patients with chronic obstructive pulmonary disease. Am J Respir Crit Care Med 1998;157:1418-22. http://dx.doi.org/10.1164/ajrccm.157.5.9709032

\title{
Every breath you take
}

\section{Liz Namukwaya', Sanctus Musafiri², *Liz Grant ${ }^{3}$}

1 Palliative Care Unit, Makerere University, Kampala, Uganda

2 Faculty of Medicine, National University of Rwanda, Butare, Rwanda

3 Global Health Academy, The University of Edinburgh, Edinburgh, UK

*Correspondence: Dr Liz Grant, Deputy Director, Global Health Academy, Medical School, Doorway 3, Teviot Place, University of Edinburgh, Edinburgh EH8 9DX, Scotland, UK Tel: +44 (0)1316514152 Fax:+44 (0)131650 9119 E-mail: Liz.Grant@ed.ac.uk

\section{See linked article by van Gemert et al. on pg 300}

Cause and effect... How much does it matter what we believe about what causes disease? And what are the implications of not making correct connections between causes and effects? The paper by van Gemert et al. ${ }^{1}$ in this issue of the PCRJ provides interesting insights into the ways in which knowledge, beliefs, and understandings about COPD and its cause and consequences determine the health and wellbeing of individuals and communities.

Chronic obstructive pulmonary disease is a major public health problem globally and a major cause of morbidity and mortality.,3 Currently the fifth leading cause of death globally, ${ }^{4}$ by 2025 it is PRIMARY CARE RESPIRATORY JOURNAL www.thepcrj.org projected to become the fourth leading cause, severely affecting those living in low and middle income countries. Increasingly poverty is identified as a risk factor for COPD, but its association with other risk factors for COPD remains unclear. ${ }^{3}$ Tobacco smoking is the wellestablished risk factor for development of COPD globally, with an estimated $80-90 \%$ risk. 5.6 The decline in lung function of susceptible smokers is twice that of non-smokers, and the pattern of cigarette smoking has changed globally, rising at a rate of $2 \%$ in low income countries. ${ }^{7}$ However, a significant number of patients with COPD, especially in low income countries in Africa, do not smoke, and the main risk factor for COPD in rural areas in Asia, South America and Africa is biomass smoke, where $90 \%$ of the rural population rely on biomass fuels for cooking. ${ }^{8-10}$ Other risk factors include previous tuberculosis (TB) infection and other respiratory infections in childhood. ${ }^{11}$

However, COPD is under-recognised in low and middle income countries by both patients and health professionals. ${ }^{3}$ This is partly due to lack of diagnostic tools, ${ }^{12}$ but it is also due to a lack of knowledge about the nature and the prognosis of the disease, and culturallyinfluenced attitudes towards the risk factors causing the disease and the symptoms of illness.

In one of the first studies of its kind, van Gemert et al. ${ }^{1}$ report the views about COPD in a rural district of Uganda, a low income country. Through 10 focus group discussions of groups of women, groups of men, and mixed groups, beliefs, attitudes and understanding of 
respiratory illness, the use of biomass fuels, tobacco smoking, the influence of gender on health, and the use of health services were explored. Almost all households were exposed to biomass fuel through indoor cooking with inadequate ventilation. Women and children were particularly affected: children under 5 stay close to their mothers for care, and traditions expect young girls to learn early how to cook. Few understood the consequences of this early exposure.

The authors found that the participants recognised 'asthma' and TB but had not heard the term 'COPD' despite cough being common among smoking men and non- smoking women and children. 'Some related smoking to breathing problems, and some of the women in the focus groups identified that firewood smoke might be the cause of breathing problems. But the strong message emerging from the focus groups was that women were expected to cook with wood even if they had chronic cough; cooking was the work of women - it was their role to provide food.

A stark difference emerged between those living in tobacco growing areas and those in non-tobacco areas. Among the nonsmoking communities chronic cough was often associated with TB and was stigmatised. Wheezing and shortness of breath were considered serious and contagious and patients did not want to be identified with these symptoms. This delayed their seeking of health care. But in tobacco growing areas chronic cough was not even considered a health problem because it had become so much part of normal life. Most men and elderly women smoked tobacco; many believed smoking cigarettes was safe but associated smoking tobacco leaves with danger. Men smoked anywhere they wanted and smoked indoors in the presence of children, exposing their families to tobacco smoke every night; women had no decision-making power.

Treatment for COPD was minimal. ${ }^{1}$ Participants reported that both traditional (local herbs) and modern treatment had poor results and often lack of finance prevented families accessing drugs. There was a lack of understanding of what needed to be treated and what treatments would and could do. Trust in health centres was low, especially as drugs for chronic respiratory symptoms were often out of stock.

The tragedy for sub-Saharan Africa is that this small study in this one region in Uganda is unlikely to be unique. Anecdotally we know that stigma and fear of TB leads to hidden illness. We know that men make behavioural decisions that negatively influence the health of the whole household, though these decisions are often made not from intent but from habit, from cultural and social traditions and lack of knowledge about cause and effect. We know that even when communities are aware of the danger of behaviours - e.g. cooking indoors with biomass fuels - the options for adopting alternative behaviors are simply not available. And not cooking food is not an option. We know that in most African countries there are no standard protocols for assessing and managing chronic respiratory diseases, and the services that exist do not reach most of the population affected by poverty. Treatments are sparse. Essential drugs are unavailable or inaccessible because of cost. A study in Ethiopia reported that many traditional asthma treatments such as ingestion of raw beaten eggs or smoking dry excreta of elephants are used. ${ }^{13}$

A major public education initiative is needed to address the knowledge gap about COPD. Given that the dominant risk factors for COPD cannot easily be removed or avoided (as they are such an integral part of many people's lives) a new approach is needed. Two factors dominate: tobacco smoking, and the use of biomass fuels. Few in sub-Saharan Africa are aware of the role played by tobacco smoking as a cause of chronic respiratory diseases. Making connections between cause and effect - exposing the link between smoking and disease, between indoor biomass fuel smoke and chronic symptoms - is essential, but this sensitisation to the dangers of smoke must be supported by empowerment measures. Therefore new multidisciplinary approaches towards prevention must not only involve health professionals but also policy makers and cultural leaders. Issues of poverty, unhelpful cultural practices, women's lack of decision-making power and control, and the vulnerability of households, all need to be addressed simultaneously if there is to be adequate risk reduction. Health systems need to be strengthened to be able to diagnose, treat and manage COPD correctly in order to improve patients' confidence in their health care and to provide essential drugs such as inhaled corticosteroids and bronchodilators that are essential for the treatment of airway diseases. And, as demonstrated by both this study and the authors' previous study, ${ }^{14}$ there is enormous value in using qualitative methods to analyse social systems and to elicit patients' views on decision-making processes within households.

Conflicts of interest The authors declare that they have no conflicts of interest in relation to this article.

Commissioned article; not externally peer-reviewed; accepted12th August 2013; online 21st August 2013

C 2013 Primary Care Respiratory Society UK. All rights reserved http://dx.doi.org/10.4104/pcrj.2013.00079

Prim Care Respir J 2013; 22(3): 265-267

\section{References}

1. van Gemert F, Chavannes N, Nabadda N, Luzige S, Kirenga B. Impact of chronic respiratory symptoms in a rural area of sub-Saharan Africa: an in-depth qualitative study in the Masindi district of Uganda. Prim Care Respir J 2013;22(3):300-05. http://dx.doi.org/10.4104/pcrj.2013.00064

2. World health report. Geneva: World Health Organisation. Available at URL http://www.who.int/respiratory/copd/burden/en/

3. From the Global Strategy for the Diagnosis, Management and Prevention of COPD, Global Initiative for Chronic Obstructive Lung Disease (GOLD) 2013. Available from: http://www.goldcopd.org/.

4. Mathers CD, Dejan L. Projections of global mortality and burden of disease from 2002 to 2030. PLoS medicine 2006;3(11):e442.

http://dx.doi.org/10.1371/journal.pmed.0030442

5. Fletcher C, Peto R. The natural history of chronic airflow obstruction. BMJ 1977;1: 1645-48. http://dx.doi.org/10.1136/bmj.1.6077.1645

6. Kohansal R, Martinez-Camblor P, Agusti A, Buist AS, Mannino DM, Soriano JB. The natural history of chronic airflow obstruction revisited: an analysis of the Framingham offspring cohort. Am J Respir Crit Care Med 2009;180:3-10. http://dx.doi.org/10.1164/rccm.200901-00470C

7. Chang Yeung M, Ait-Khaled N, White N, Ip MS, Tan WC. The burden and impact of COPD in Asia and Africa. Int J Tuberc Lung Dis 2004;8(1):2-14

8. Perez-Padilla R, Regalado J, Vedal S, et al. Exposure to biomass smoke and chronic airway disease in Mexican women. A case-control study. Am J Respir Crit Care Med 1996;154:701-06. http://dx.doi.org/10.1164/ajrccm.154.3.8810608

9. Dossing M, Khan J, al-Rabiah F. Risk factors for chronic obstructive lung disease in 
Saudi Arabia. Respir Med 1994;88:519-22.

http://dx.doi.org/10.1016/S0954-6111(05)80334-8

10. WHO. The energy access situation in developing countries: a review focusing on the least developed countries and sub-Saharan Africa. World Health Organization, 2009

11. Allwood BW, Myer L, Bateman ED. A Systematic Review of the Association between Pulmonary Tuberculosis and the Development of Chronic Airflow Obstruction in Adults. Respiration 2013;86(1):76-85

http://dx.doi.org/10.1159/000350917
12. Mehrotra A, Oluwole AM, Gordon SB. The burden of COPD in Africa: a literature review and prospective survey of the availability of spirometry for COPD diagnosis in Africa. Trop Med Int Health 2009;14(8):840-8. http://dx.doi.org/10.1111/j.1365-3156.2009.02308.x

13. Teklu B. Bronchial asthma at high altitude, a clinical and laboratory study in AddisAbaba. Thorax 1989;44(7):586-7. http://dx.doi.org/10.1136/thx.44.7.586

14. Van Gemert F, van der Molen $T$, Jones $R$, Chavannes $N$. The impact of asthma and COPD in sub-Saharan Africa. Prim Care Respir J 2011;20:240-8. http://dx.doi.org/10.4104/pcrj.2011.00027

\section{The flow-volume loop in inducible laryngeal obstruction: one component of the complete evaluation}

\author{
*Michael J Morris', Kent L Christopher ${ }^{2}$ \\ 1 Pulmonary and Critical Care Medicine, San Antonio Military \\ Medical Center, Fort Sam Houston, Texas, USA \\ 2 Pulmonary and Critical Care Medicine, University of Colorado \\ School of Medicine, Denver, Colorado, USA \\ *Correspondence: Michael J. Morris MD, Pulmonary/Critical \\ Care Medicine, San Antonio Military Medical Center, Fort Sam \\ Houston, 78234, Texas, USA \\ Tel: 00 (1) 210-916-3027 Fax: 00 (1) 210-916-4721 \\ E-mail: michael.j.morris34.civ@mail.mil
}

\section{See linked article by Christensen et al. on pg 306}

Since the initial description of the flow-volume loop (FVL) by Miller and Hyatt in the early 1970's as a clinical predictor of upper airway obstruction (UAO), ${ }^{1}$ its utility in clinical practice has been debated. Early case series' suggested that the FVL might be a sensitive indicator of $\mathrm{UAO}^{2}$ Combining the FVL appearance with measurements of the forced mid-expiratory to mid-inspiratory flow ratios $\left(\mathrm{FEF}_{50} / \mathrm{FIF}_{50}\right)$ was reported to separate upper airway lesions into fixed lesions (ratio of 0.85 ), variable extrathoracic obstruction (ratio of 2.20) with inspiratory limb truncation, and variable intrathoracic obstruction (ratio of 0.32 ) with expiratory limb truncation. ' The 2005 guidelines on spirometry emphasise examination of the FVL for evidence of intrathoracic or extrathoracic UAO as an integral part of the interpretation. ${ }^{3}$

The diagnostic utility of the FVL can be variable. Since the FVL requires a maximal inspiratory and expiratory vital capacity manoeuvre, the most common cause of an abnormal FVL is submaximal patient effort or inadequate patient instruction in properly performing the required technique. Numerous conditions consistent with either a fixed or intermittent UAO can be considered for diagnosis or followed post-diagnosis using the FVL appearance and associated spirometric findings such as the $\mathrm{FEF}_{50} / \mathrm{FIF}_{50}$. Suspicion should be increased when abnormal test results occur in conjunction with symptoms such as dyspnoea and noisy breathing, or physical examination identifying stridor or wheezing. Diagnostic confirmation of an UAO can be made with airway imaging, laryngoscopy, or bronchoscopy. Anatomic obstructions such as airway tumors, tracheal stenosis, and bilateral vocal cord paralysis are specific disease processes where the FVL can be instrumental in raising suspicions for underlying disease if there is significant flow limitation. ${ }^{4}$ However, imaging techniques such as computed tomography (CT) scanning can detect early anatomic lesions without significant flow limitation or FVL findings. Exterior compression of the trachea from goitres or anterior mediastinal masses may demonstrate FVL abnormalities depending upon patient positioning. Upright and supine spirometry with FVL was first advocated in 1984 to predict airway compromise in the supine position but limited combined data supported this approach. ${ }^{5}$ After the 1983 publication of the initial series of vocal cord dysfunction (VCD) patients, ${ }^{6}$ emphasis has shifted to using the FVL to identify symptomatic episodes of inducible laryngeal obstruction (ILO) due to upper airway disorders such as VCD and exercise-induced laryngeal obstruction (EILO).

Limited data exist on the predictive value of FVL appearance in determining the presence or absence of induced laryngeal obstruction. We previously reviewed inspiratory FVL appearance in our institution and identified $2.6 \%$ of properly performed spirometry with repeatable (two of three efforts) inspiratory $\mathrm{FVL}$ abnormalities. Of these 69 patients, only $17 \%$ had a documented follow-up evaluation. The cause of the abnormal FVL was identified in 52\%, which consisted primarily of VCD patients. ${ }^{7}$ For most ILOs, the FVL is likely to be normal when testing is performed in an asymptomatic patient. Due to the intermittent nature of VCD symptoms, corresponding inspiratory FVL abnormalities were described in approximately $25 \%$ of all reported patients. ${ }^{8}$ Additional study of identification of VCD by FVL appearance was poorly predictive when examined by three pulmonologists blinded to patient history or examination. ${ }^{9}$ It is very important to distinguish EILO from exercise-induced bronchospasm in elite athletes, and the FVL may be suggestive in these patients. McFadden first described "choking" in seven elite athletes who were eventually diagnosed with VCD after negative asthma bronchoprovocation testing; post-bronchoprovocation FVL abnormalities were seen in all seven patients. ${ }^{10}$

In the study by Christensen et al. in this issue of the PCRJ, ${ }^{11}$ the authors attempted to demonstrate whether the FVL and associated measurements of several inspiratory flows and the $\mathrm{FEF}_{50} / \mathrm{FIF}_{50}$ ratio 